\title{
How Do We Balance Tensions Between COVID-19 Public Health Responses and Stigma Mitigation? Learning from HIV Research
}

\author{
Carmen H. Logie ${ }^{1,2}$ • Janet M. Turan ${ }^{3}$
}

Published online: 7 April 2020

(c) Springer Science+Business Media, LLC, part of Springer Nature 2020

We are not being invaded. The body is not a battlefield. The ill are neither unavoidable casualties nor the enemy. We-medicine, society—are not authorized to fight back by any means whatever. - Sontag (1 p. 180)

Sontag's quotation above from 'AIDS and its metaphors' [1] reminds us to expose, and disengage from, constructions of illness that propagate fear. We are called to address the fear of COVID-19 by correcting misinformation [2,3]. While misinformation is indeed a driver of fear and stigma, other underlying facilitators produce stigma $[4,5]$ and need to be considered in stigma mitigation. HIV research and an understanding of the historical construction of illness can be leveraged to mitigate COVID-19 stigma. COVID-19 public health responses-essential for prevention and containment $[6,7]$-also have the potential to exacerbate stigma [8]. We outline four tensions between COVID19 containment and stigma mitigation, and offer possible ways forward.

\section{How We Approach Illness Matters}

There is a long history of othering in conceptualizing illness, whereby the sick are separated from the healthy [9]. Responses to illnesses are shaped by their unpredictability and perceived contagion [10]. Illnesses have been constructed as both evil predators and personal responsibilities, contributing to social rejection $[1,10]$. Jones [11] described

Carmen H. Logie

carmen.logie@utoronto.ca

1 Factor-Inwentash Faculty of Social Work, University of Toronto, 246 Bloor Street West, Toronto, ON M5S 1V4, Canada

2 Women's College Research Institute, Women's College Hospital, Toronto, Canada

3 Department of Health Care Organization and Policy, School of Public Health, University of Alabama at Birmingham, Birmingham, USA historical examples of how responses to epidemics unfold. At first there may be a lack of recognition of the seriousness of the problem, followed by public responses that are grounded in moralistic and mechanistic interpretations. This could be followed by government actions, such as quarantine, that can exacerbate power imbalances between civilians and the state. Who and what is respected in a society become clear in an epidemic [11].

Social reactions to 'plagues' reveal the perception that the illness originates elsewhere $[1,10,11]$. Blaming a foreign other for epidemics is commonplace throughout history. Sontag described "a link between imagining disease and imagining foreignness...illness is a species of invasion" (1 p. 48). Military metaphors-including such terms as targets and fighting-frame illnesses as society's invasive, wicked infiltrators that spur paranoia and command social order, and in turn can exacerbate pre-existing social inequities [1, 10, 12]. Medical education constructs the body as a battlefield that requires us to strengthen our defense system [12].

\section{Tensions Between Stigma Mitigation and COVID-19 Public Health Responses}

Historical and current approaches to illness-including HIV - can inform COVID-19 stigma reduction. Tensions between stigma mitigation and COVID-19 containment emerge regarding: physical distancing, travel restrictions, misinformation, and engaging affected communities.

First, othering can result in social distancing through reduced interaction with stigmatized persons [13]. Yet to slow the spread of COVID-19, it is necessary to practice public health recommended physical distancing-avoiding close contact and maintaining $1 \mathrm{~m}$ distance from others [7]. While an integral component of containment [6, 7], how can we ensure that physical distancing does not exacerbate othering, avoidance, and mistreatment toward persons associated with COVID-19? Stigma-reduction messaging can carefully reflect the evolving patterns of COVID-19 risk to 
foster empathy while simultaneously transforming physical distancing into a normal and sustained practice until the pandemic is over. While there are no direct parallels to HIV with physical distancing, HIV has long contended with the tension between negotiating intimacy and physical connection in a pandemic. The 1983 publication "How to have sex in an epidemic: One approach" explored care, love, and intimacy as reasons for safer sex motivation [14]. Pleasure (not only fear of HIV infection) is key to engaging in HIV preventive practices $[15,16]$. Similarly, UNAIDS [8] and WHO [3] suggest that building connections via kindness and caring (rather than simply fear of COVID-19 infection) can motivate uptake of non-stigmatizing physical distancing.

COVID-19 travel bans, lockdowns, and movement restrictions are being implemented across dozens of countries. Movement bans and quarantines are often legally enforced, for instance by military and municipal police. These approaches help with COVID-19 containment and allow greater responsiveness to overstretched health systems. Yet COVID-19 travel restrictions may also facilitate stigma and xenophobia by reproducing the social construction of illness as a foreign invasion, in turn reinforcing social hierarchies and power inequities $[1,10]$ —at times through authoritarian means [11]. Enforcement of travel bans, movement restrictions, and quarantines may disproportionately affect already stigmatized persons, including homeless persons [17], persons who are incarcerated [18], migrants and refugees [19], undocumented immigrants [20], and racial minorities [8]. There are global media reports of arrests for COVID-19 transmission [21-25]. Travel bans also exist for HIV: 48 countries currently maintain travel restrictions for people with HIV, reflecting the pervasiveness and persistence of social control measures that perpetuate stigma [26]. HIV transmission has been criminalized [27] in 72 countries [28]: such policies are not evidence-based and harm the health and human rights of people with HIV [29, 30]. Lesbian, gay, bisexual and transgender (LGBT) persons, sex workers, and people who use drugs, experience criminalization that reduces access to employment, housing, and healthcare, and exacerbates risks for violence and practices that elevate HIV exposure [31-34]. As an alternative approach, COVID-19 travel bans and quarantine could include anti-stigma and anti-xenophobia public messaging and training of legal authorities [4, 35]. Furthermore, UNAIDS recommends that in lieu of criminalization for breaching COVID-19 public health policies, approaches should focus on empowering and strengthening communities to support persons to protect their own and one other's health [8].

Third, it is necessary to address misinformation and lack of awareness regarding COVID-19-but not sufficient. Stigma mitigation also needs to tackle facilitators such as social inequities [4], including racism and xenophobia. Public health strategies that improve access to COVID-19 testing and employment sick leave benefits have the potential to reduce stigma. Yet addressing underlying social inequities and healthcare access require long-term investment in transforming values, laws, and policies. The tension therefore emerges between the immediate-and faster-work of providing information in the midst of the COVID-19 pandemic and the need for long-term investment in reducing social inequities. Stigma-reduction strategies for HIV and other health issues have largely targeted intrapersonal and interpersonal dimensions, far fewer have addressed structural factors such as legal issues, policies, and rights [36]. Interventions should address both drivers (knowledge, misinformation) and facilitators (health policies, institutional practices) [37]. We know from an extensive body of HIV-related stigma research that multiple stigma dimensions can negatively impact health practices and outcomes [5]. COVID-19 stigma mitigation can therefore consider enacted stigma - acts of discrimination and mistreatment, felt-normative stigma-demeaning community norms and values, internalized stigma - the ways that persons accept negative perspectives toward a group(s) they may belong to, and anticipated stigma-concerns that one will experience future discrimination and bias [5]. We have seen international financing for HIV decline [38], threatening the global ambition to end the pandemic. This is not unique to HIV: the United Nations Population Fund also reported significant funding shortfalls for humanitarian relief in 2019 [39]. We need to act now to harness political investment in challenging the social inequities that exacerbate COVID-19's impact on marginalized communities_-such as refugees [19] and undocumented immigrants [20] — rather than waiting for the pandemic to subside when there may be a decreased sense of commitment, urgency, and momentum.

Fourth, we need to engage persons most affected by COVID-19 in developing stigma mitigation strategies, yet they may experience social and health disparities that present barriers to research participation. Lived experiences of COVID-19 and other intersecting stigmas $[4,5,40]$ can inform contextually specific and stigma-informed public health approaches. For instance, gendered roles as family caregivers and front-line healthcare workers may elevate women's exposure to COVID-19 [41], requiring a genderbased analysis of social and health impacts of public health measures such as quarantine. Past pandemics such as Ebola reduced women's access to maternal and child health services [42], abortion [43], and reduced uptake of HIV services [44]. Social disparities are associated with health disparities. Persons experiencing stigma, such as people newly diagnosed with HIV [45] and LGBT persons [46], are disproportionately impacted by depression. Although research is nascent, the stress from COVID-19 stigma may have analogous mental health impacts [47, 48], including on healthcare providers $[49,50]$. Strategies therefore need 
to factor in multiple health conditions and social identities to understand and reduce COVID-19 stigma. A syndemics approach could be useful in mapping the ways that social inequities contribute to the production of multiple interacting health issues, including COVID-19 [51]. Creative, webbased, and community-engaged strategies can aim to reduce participation barriers to involve persons most impacted by COVID-19 stigma in research and program development (e.g., addressing access barriers posed by COVID-19 caregiving and/or healthcare provider roles, quarantine, mental health challenges).

We need more than information to reduce COVID-19 stigma - multi-level strategies can address underlying stigma drivers and facilitators [4]. Public health actors can challenge military metaphors and other stigmatizing language in public health messaging and media [1, 10, 12]. Applying an intersectional lens $[4,40]$ can improve understanding of the ways that COVID-19 stigma intersects with gender, race, immigration status, housing security, and health status, among other identities. Balancing tensions between stigma mitigation and COVID-19 prevention and containment can inform immediate and long-term strategies to build empathy and social justice in current and future pandemics.

Acknowledgements CHL was supported during the writing of this manuscript by a residency at the Brocher Foundation and an Eccles Fellowship at the British Library. She also receives support for her program of research from Canada Research Chairs, Canada Foundation for Innovation, and the Ontario Ministry of Research and Innovation. JMT's contribution to this research was supported by the University of Alabama at Birmingham (UAB) Center for AIDS Research CFAR and an NIH funded program (P30 AI027767) that was made possible by the following institutes: NIAID,NCI, NICHD, NHLBI, NIDA, NIA, NIDDK, NIGMS, and OAR. Funders played no role in writing this manuscript.

\section{Compliance with Ethical Standards}

Conflict of interest The authors have no conflicts of interest to declare.

\section{References}

1. Sontag S. AIDS and its metaphors. New York: Farrar, Straus and Giroux; 1989.

2. World Health Organization. WHO Director-General's opening remarks at the media briefing on COVID-19-5 March 2020 [Internet]. World Health Organization. 2020. https://www.who. int/dg/speeches/detail/who-director-general-s-opening-remarksat-the-media-briefing-on-covid-19---5-march-2020. Accessed 7 Mar 2020.

3. World Health Organization, International Federation of Red Cross and Red Crescent Societies, United Nations Children's Fund. Social Stigma associated with COVID-19 [Internet]. World Health Organization. 2020. https://www.who.int/docs/default-source/ coronaviruse/covid19-stigma-guide.pdf?sfvrsn=226180f4_2. Accessed 28 Mar 2020.
4. Stangl AL, Earnshaw VA, Logie $\mathrm{CH}$, van Brakel W, Simbayi CL, Barre I, et al. The Health Stigma and Discrimination Framework: a global, crosscutting framework to inform research, intervention development, and policy on health-related stigmas. BMC Med. 2019;17(1):31.

5. Turan B, Hatcher AM, Weiser SD, Johnson M, Smith W, Turan JM. Framing mechanisms linking HIV-related stigma, adherence to treatment and health outcomes. Am J Public Health. 2017;107(6):863-9.

6. Lancet T. COVID-19: learning from experience. The Lancet. 2020;395(10229):1011.

7. Lewnard JA, Lo NC. Scientific and ethical basis for socialdistancing interventions against COVID-19. Lancet Infect Dis. 2020. https://doi.org/10.1016/S1473-3099(20)30190-0.

8. UNAIDS. Rights in the time of COVID-19-Lessons from HIV for an effective, community-led response [Internet]. 2020. https ://www.unaids.org/en/resources/documents/2020/human-right s-and-covid-19. Accessed 31 Mar 2020.

9. Whittle H, Palar K, Ranadive NA, Hufstedler LL, Napoles T, Turan JM, Kushel M, Weiser SD. "The land of the sick and the land of the healthy": disability, bureaucracy, and stigma among people living with poverty and chronic illness in the United States. Soc Sci Med. 2017;190(Supplement C):181-9.

10. Sontag S. Illness as metaphor. New York: Farrar, Straus and Giroux; 1978 .

11. Jones DS. History in a crisis-lessons for Covid-19. N Engl J Med. 2020. https://doi.org/10.1056/NEJMp2004361.

12. Wiggins NM. Stop using military metaphors for disease. BMJ. 2012;345:e4706.

13. Goffman E. Stigma: notes on the management of spoiled identity. New York: Simon \& Shuster; 1963.

14. News from The Front Publications. How to have sex in an epidemic: one approach. New York: Tower Press; 1983.

15. Philpott A, Knerr W, Boydell V. Pleasure and prevention: when good sex is safer sex. Reprod Health Matters. 2006;14(28):23-31.

16. Castellanos-Usigli A, Braeken-van SD. The pleasuremeter: exploring the links between sexual health, sexual rights and sexual pleasure in sexual history-taking, SRHR counselling and education. Sex Reprod Health Matters. 2019;27(1):313-5.

17. Tsai J, Wilson M. COVID-19: a potential public health problem for homeless populations. Lancet Public Health. 2020;5(4):e186-e187187.

18. Kinner SA, Young JT, Snow K, Southalan L, Lopez-Acuña D, Ferreira-Borges C, et al. Prisons and custodial settings are part of a comprehensive response to COVID-19. Lancet Public Health. 2020;5(4):e188-e189189.

19. Daniels JP. Venezuelan migrants "struggling to survive" amid COVID-19. The Lancet. 2020;395(10229):1023.

20. Page KR, Venkataramani M, Beyrer C, Polk S. Undocumented U.S. immigrants and Covid-19. N Engl J Med. 2020. https://doi. org/10.1056/NEJMp2005953.

21. Flanagan R. N.L. announces 32 new COVID-19 cases; woman arrested for disobeying isolation order [Internet]. CTV News. 2020. https://www.ctvnews.ca/health/coronavirus/n-l-announces32-new-covid-19-cases-woman-arrested-for-disobeying-isolationorder-1.4867889. Accessed 28 Mar 2020.

22. Cherry P. Woman with COVID-19 arrested in Quebec City after breaking self-quarantine [Internet]. Montreal Gazette. 2020. https ://nationalpost.com/news/local-news/woman-with-covid-19-arres ted-in-quebec-city-after-breaking-self-quarantine/wcm/07164 538-315f-4aec-9ed5-d94bc728b7e3. Accessed 28 Mar 2020.

23. Tondo L. Italy charges more than 40,000 people with violating lockdown [Internet]. The Guardian. 2020. https://www.theguardia n.com/world/2020/mar/18/italy-charges-more-than-40000-peopl e-violating-lockdown-coronavirus. Accessed 28 Mar 2020. 
24. National Post Staff. 'Intentional murder': Careless COVID-19 spreaders in Italy could face homicide charges [Internet]. National Post. 2020. https://nationalpost.com/news/world/intentiona 1-murder-careless-covid-19-spreaders-in-italy-could-face-homic ide-charges. Accessed 28 Mar 2020.

25. Gerstein J. Those who intentionally spread coronavirus could be charged as terrorists [Internet]. Politico. 2020. https://www.polit ico.com/news/2020/03/24/coronavirus-terrorism-justice-depar tment-147821. Accessed 28 Mar 2020.

26. UNAIDS. Travel restrictions [Internet]. 2020. https://www.unaid s.org/en/keywords/travel-restrictions. Accessed 31 Mar 2020.

27. HIV Criminalization [Internet]. Canadian HIV/AIDS Legal Network. 2020. https://www.aidslaw.ca/site/our-work/criminalization /?lang=en. Accessed 31 Mar 2020.

28. Cameron S, Bernard E. Advancing HIV Justice 3: growing the global movement against HIV criminalisation. Amsterdam: HIV Justice Network; 2019.

29. The Lancet HIV. HIV criminalisation is bad policy based on bad science. Lancet HIV. 2018;5(9):e473.

30. Galletly C, Lazzarini Z, Sanders C, Pinkerton SD. Criminal HIV exposure laws: moving forward. AIDS Behav. 2014;18(6):1011-3.

31. Cornell M, Dovel K. Reaching key adolescent populations. Curr Opin HIV AIDS. 2018;13(3):274-80.

32. Schwartz SR, Nowak RG, Orazulike I, Keshinro B, Ake J, Kennedy S, et al. The immediate effect of the Same-Sex Marriage Prohibition Act on stigma, discrimination, and engagement on HIV prevention and treatment services in men who have sex with men in Nigeria: analysis of prospective data from the TRUST cohort. Lancet HIV. 2015;2(7):e299-306.

33. Shannon K, Crago A-L, Baral SD, Bekker L-G, Kerrigan D, Decker MR, et al. The global response and unmet actions for HIV and sex workers. The Lancet. 2018;392(10148):698-710.

34. Buse K, Albers E, Phurailatpam S. HIV and drugs: a common, common-sense agenda for 2016. Lancet Glob Health. 2016;4(5):e292-e293293.

35. Chief Public Health Officer of Canada. Addressing stigma: towards a more inclusive health system. The Chief Public Health Officer's Report on the State of Public Health in Canada 2019. Public Health Agency of Canada; 2019.

36. Rao D, Elshafei A, Nguyen M, Hatzenbuehler ML, Frey S, Go VF. A systematic review of multi-level stigma interventions: state of the science and future directions. BMC Med. 2019;17(1):41.

37. Nyblade L, Stockton MA, Giger K, Bond V, Ekstrand ML, Lean RM, et al. Stigma in health facilities: why it matters and how we can change it. BMC Med. 2019;17(1):25.

38. UNAIDS. Without sustainable financing the AIDS response will fail [Internet]. 2019. https://www.unaids.org/en/resources/ presscentre/featurestories/2019/september/20190926_finance. Accessed 1 Apr 2020

39. United Nations Population Fund. Humanitarian Action 2019 Overview [Internet]. UNPFA. 2019. www.unfpa.org/humanitari an-action-2019-overview. Accessed 1 Apr 2020.
40. Logie CH, L1 J, Tharao W, Loutfy MR. HIV, gender, race, sexual orientation, and sex work: a qualitative study of intersectional stigma experienced by HIV-positive women in Ontario Canada. PLOS Med. 2011;8(11):e1001124.

41. Wenham C, Smith J, Morgan R. COVID-19: the gendered impacts of the outbreak. The Lancet. 2020;395(10227):846-8.

42. Delamou A, Ayadi AME, Sidibe S, Delvaux T, Camara BS, Sandouno SD, et al. Effect of Ebola virus disease on maternal and child health services in Guinea: a retrospective observational cohort study. Lancet Glob Health. 2017;5(4):e448-e45757.

43. Hussein J. COVID-19: what implications for sexual and reproductive health and rights globally? Sex Reprod Health Matters. 2020. https://doi.org/10.1080/26410397.2020.1746065.

44. Jacobs GP, Bhat P, Owiti P, Edwards JK, Tweya H, Najjemba R. Did the 2014 Ebola outbreak in Liberia affect HIV testing, linkage to care and ART initiation? Public Health Action. 2017;7(Suppl 1):S70-S7575.

45. Bhatia R, Hartman C, Kallen MA, Graham J, Giordano TP. Persons newly diagnosed with HIV infection are at high risk for depression and poor linkage to care: results from the steps study. AIDS Behav. 2011;15(6):1161-70.

46. Logie C, Lacombe-Duncan A, Wang Y, Levermore K, Jones N, Ellis T, et al. Adapting the psychological mediation framework for cisgender and transgender sexual minorities in Jamaica: implications from latent versus observed variable approaches to sexual stigma. Soc Sci Med. 2020;245:112663.

47. World Health Organization. Mental health and psychosocial considerations during the COVID-19 outbreak [Internet]. 2020. WHO/2019-nCoV/MentalHealth/2020.1. Accessed 31 Mar 2020.

48. Ho CS, Chee CY, Ho RC. Mental health strategies to combat the psychological impact of COVID-19 beyond paranoia and panic. Ann Acad Med Singap. 2020;49(1):1-3.

49. Adams JG, Walls RM. Supporting the health care workforce during the COVID-19 global epidemic. JAMA Netw Open. 2020. https://doi.org/10.1001/jama.2020.3972.

50. Lai J, Ma S, Wang Y, Cai Z, Hu J, Wei N, et al. Factors associated with mental health outcomes among health care workers exposed to coronavirus disease 2019. JAMA Netw Open. 2020;3(3):e203976.

51. Singer M. A dose of drugs, a touch of violence, a case of AIDS: conceptualizing the SAVA syndemic. Free Inq Creat Sociol. 2000;28(1):13-24.

Publisher's Note Springer Nature remains neutral with regard to jurisdictional claims in published maps and institutional affiliations. 